\title{
Génétique moléculaire et sauce tomate
}

\section{Les perspectives nouvelles des ARN antisens en génétique moléculaire végétale}

Les industriels de l'agro-alimentaire se trouvent devant un redoutable dilemme: soit vendre des tomates mûres et savoureuses à souhait... dont plus de la moitié sera écrasée au cours des manipulations et du transport, soit proposer des fruits verts, durs, totalement insipides... mais faciles à conditionner. Il semble que ce soit cette dernière solution qui ait été adoptée généralement aux USA [1]. Le problème vient de ce que la maturation de la tomate s'accompagne d'une synthèse importante de l'enzyme polygalacturonase, qui digère les parois des cellules végétales, effondre les travées assurant la rigidité de l'architecture du fruit et aboutit à cet objet mou ayant une tendance naturelle à s'écraser, et pas seulement sur le visage des acteurs, des chanteurs... ou des premiers ministres contestés. Jusqu'à présent, la solution à un seul de ces problèmes avait été trouvée : le fruit vert traité à l'éthylène rougit... ce qui ne modifie en rien ses piètres qualités gustatives.

La solution génétique consisterait à dissocier la maturation du fruit de l'hyperactivité de l'enzyme responsable de son ramollissement. Cela est maintenant possible - et en partie testé par deux équipes anglaises grâce à l'utilisation d'ARN antisens complémentaire du messager de la polygalacturonase [2]. La tomate étant un dicotylédone, le système classique de transformation par le plasmide $\mathrm{Ti}$ de la bactérie du sol Agrobacterium tumefaciens fonctionne parfaitement. Des plantes transgéniques ont par conséquent été créées par introduction d'un transgène constitué de l'ADN codant pour l'ARN antisens, contrôlé par le promoteur fort du gène de l'ARN $35 \mathrm{~S}$ du virus de la mosaïque du chou-fleur et terminé par l'extrémité 3' du gène de la nopaline synthase. Il s'agit là d'une construction parfaitement classique en génétique végétale... hormis le fait qu'elle comporte un $m / s n^{\circ} 9$ vol. 4 , novembre 88
ADN transcrit en un ARN antisens. Les tomates transgéniques ont une réduction de $90 \%$ de l'activité de la polygalacturonase, associée à une diminution du même ordre de la concentration du messager. Le mécanisme de cette baisse de la quantité de messager peut être une interférence de l'ARN antisens avec la maturation nucléaire des transcrits primaires, ou une instabilité du messager cytoplasmique partiellement double brin.

L'intérêt de cette expérience dépasse le douloureux problème de la saveur des tomates; il est en fait de confirmer l'efficacité dans les plantes des ARN antisens, déjà démontrée de façon spectaculaire dans les pétunias par une équipe néerlandaise. L'expression, dans des pétunias transgéniques, issus d'une fleur parentale rouge, d'un ARN antisens complémentaire du messager de la chalcone synthase (enzyme principale de la synthèse des flavonoïdes, responsables de la couleur de la fleur) aboutit à des fleurs allant du rose au blanc [3, 4]. Des succès peuvent aussi être obtenus avec le tabac.

Les raisons de ces succès répétés, alors qu'une même approche s'est révélée peu efficace chez les souris, restent énigmatiques. On peut supposer que le promoteur végétal utilisé est très fort. Peut-être existe-t-il également dans les plantes un système nucléasique particulièrement efficace pour dégrader l'ARN double brin. Quoiqu'il en soit, nul doute que cette stratégie, utilisant les $\mathrm{ARN}$ antisens ou les ribozymes naturellement actifs dans les plantes $(\mathrm{m} / \mathrm{s}$ $n^{\circ} 8$, vol. 4, p. 522), est appelée à connaître un impérieux développement en recherche végétale fondamentale aussi bien qu'en biotechnologie lorsqu'il s'agira d'inhiber ou de freiner l'expression d'un gène aux effets défavorables. Ainsi peut-on imaginer des plantes pratiquement imputrescibles, du café sans caféine et du tabac sans nicotine! Des ARN antisens antiviraux pourraient aussi protéger les plantes contre une grande variété d'infections.

A. $\mathbf{K}$

1. Roberts L. Genetic engineers build a better tomato. Science 1988 ; 241 : 1290.

2. Smith CJS, Watson CF, Ray J, et al. Antisense RNA inhibition of polygalacturonase gene expression in transgenic tomatoes. Nature 1988 ; 334 : 724-6.

3. Van der Krol AR, Lenting PE, Veenstra J, et al. An anti-sense chalcone synthase gene in transgenic plants inhibits flower pigmentation. Nature $1988 ; 333$ : 866-9.

4. Lichenstein C. Anti-sense RNA as a tool to study plant gene expression. Nature 1988 ; $333: 801-2$.

\section{BRĖVES}

Les stratégies utilisées pour créer la tolérance immunologique sont variées. Les clones de lymphocytes $B$ et $T$ de spécificité dirigée contre un auto-antigène (antigène du self) sont spécifiquement détruits ou inhibés au cours de l'ontogenèse. Lorsque deux souris transgéniques, exprimant l'une le lysozyme de blanc d'œuf et l'autre un fort anticorps IgM ou IgD dirigé contre ce lysozyme, sont croisées, une tolérance immunologique spécifique s'établit chez les descendants exprimant les deux transgènes. Les cellules $B$ autoréactives ne sont cependant pas détruites, mais ne sécrètent plus d'anticorps antilysozyme[1]. L'IgM de surface antilysozyme est pratiquement absente alors que l'IgD continue d'être synthétisée et exprimée à un haut niveau. Les mécanismes de ces modifications complexes et concertées (absence de sécrétion d'anticorps, inversion de l'équilibre entre les IgM et les IgD de surface) sont totalement inconnus. Il pourrait y avoir une corrélation entre l'expression d'IgD de surface et la tolérance à l'antigène.

[1. Goodnow CC, et al. Nature 1988 ; 334 : 676-82.]

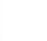
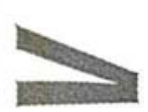
(1)

\section{.}
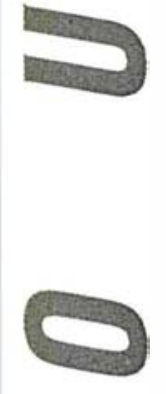

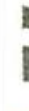

